\title{
Services for student well-being in academic libraries: Three challenges
}

\begin{abstract}
There has been a wave of interest in UK academic libraries in developing services to support student well-being. This paper identifies three fundamental and interrelated issues that need to be addressed to make such initiatives effective and sustainable. Firstly, well-being has to be defined and the impacts of interventions must be measured in appropriate ways. Secondly, there is a need to identify the true nature of the underlying social problem around well-being. Thirdly, relevant approaches to the issue need to be located within the professional knowledge base of librarianship.
\end{abstract}

\section{Introduction}

The last two or three years have seen a trend for academic libraries in the UK to develop activities explicitly designed to promote student well-being. Several of these activities seem to be fairly well-aligned with the longstanding image of the academic library as a collection, for example providing fiction reading for pleasure (Porritt, 2019). . Many others have gone far beyond what might be considered usual academic library services such as hosting creative activities including the provision of colouring books and jigsaws, animal petting, and exercise classes.

A number of professional events have been run round the theme of well-being and reports of such activities are emerging in the professional literature, eg four articles in the special issue of ALISS Quarterly $(14,2)$ on the topic. Another good illustration of the kind of thinking that lies behind these initiatives is the entertaining short piece explaining recent work around student well-being at the Library of the University of Warwick (Brewerton and Woolley, 2017). This article is based on a critical reading of these five papers.

While respecting the authors' sincerity and accepting the genuine benefits to users arising from such activities, there seem to be a number of fundamental issues with the argument made in these papers that we believe represent general challenges with the agenda around well-being 
for academic libraries. Specifically, from a close reading of the papers we identify three fundamental, interrelated issues that library services around well-being have to address, namely: the need to define well-being and to evaluate the impacts of interventions in appropriate ways; the need to identify the true nature of the problem around well-being; and the need to locate solutions to the problem within the professional knowledge base. We share librarians' belief that academic libraries do already contribute to student well-being, and can do so more, however, we argue that the issues exemplified in this emerging literature need to be addressed if libraries' contribution to well-being is to be ensured.

\section{"Study happy"}

One of the first descriptions on well-being related activities in a UK academic library is Brewerton and Woolley (2017) which reports activities run from 2014 onwards by University of Warwick libraries under the banner "study happy". The paper is ordered around the questions why, who and what. The first pages develop an argument about why services around well-being might be relevant to an academic library. They explain that organisationally the well-being related activities are offered by their Community Engagement team. The authors chart connections to library and university strategy. They also propose an underlying link to Maslow's (1943) theory of the hierarchy of needs. The short section about "who?", extends this justification, seeking to account for why the library is the right place to host such services. The section on "what?" explains the kinds of activities they have organised, often in conjunction with other student-facing services, including origami and adult colouring, learning to play the ukulele, walking and yoga and patting dogs. The paper is amply illustrated with photographs.

Brewerton and Woolley's (2017) paper is one of the first papers to report on well-being work in libraries in the UK, however a number of previous papers from American authors have explored activities such as therapy dog programmes (e.g. Bell, 2013), yoga sessions in the library (Varman and Justice, 2015; see also Casucci and Baluchi, 2019) and more recently, napping (Wise, 2018). Subsequently, in the UK a number of professional events have enabled librarians

to share experiences of offering these services. Emerging from these, there is the beginnings of a professional literature on the topic. For example, the magazine for the Association of Librarians and Information professionals in the social sciences, ALISS quarterly, published a special issue on the topic in January 2019. Papers in the issue echo the themes in Brewerton and Woolley (2017). Houghton (2019) explores the benefits of bringing owls into the library at 
Middlesex University. Smith (2019) explains how the library at Keele University is collaborating with other services around well-being at examination time. Another paper describes the library's involvement in the festival of Wellbeing at Teesside University (Porritt, 2019). The papers contain a lot of practical advice on how to organise such events. Such work is paralleled across the Galleries, Libraries, Archives and Museums (GLAM) sector, with work in museums (Lackoi et al. 2016 and Desmarais et al. 2018) and archives (Brunton, 2018) exploring how these institutions impact well-being.

In this paper we use this emerging UK professional literature as a convenient starting point to enter the argument. We would emphasise that our dispute is not with these well-meaning authors. We agree that libraries have a potentially important place in student well-being. The many activities the authors have organised may well have positively impacted student wellbeing. Further, their works are typically a means of practical knowledge sharing, not intended to be heavily-theorised justification for these services. A critique of this work may seem unfair. However, we suggest that analysis of these papers assists in identifying the three fundamental issues with the case for library services to support well-being. Our hope is that by unpacking the argument, we can place the academic library role on a much sounder, sustainable basis that facilitates genuine engagement with student well-being.

\section{Defining well-being and evaluating the impacts of interventions in appropriate ways}

The first issue apparent from a close reading of the papers is that they fail to convincingly define the core concept of well-being that the activities they are organising are trying to address. One aspect of this is reflected in the terminology they employ. Houghton (2019) talks about the events needing to be "fun". Brewerton and Woolley (2017) use a number of terms that are poorly-defined and not interchangeable, including "stress" (a physiological response to an internal or external stressor) and "being happy" (a self-defined emotional reaction). Furthermore, in reaching out for a theoretical justification for their activities they use a rather idiosyncratic reference point: Maslow's (1943) hierarchy of needs. A stock reference in the management literature, as they themselves point out, it is not one that this is widely referenced in the study of well-being. Maslow's (1943) hierarchy of needs is a theory of motivation (what makes humans act) rather than a theory of well-being, and drawing on it in this context appears 
to be an attempt to give scientific basis or credence to activity rather than a genuine underpinning principle for it.

Among their rather eclectic list of sources for understanding well-being, Brewerton and Woolley (2017) do also draw on a commonly used, perhaps even dominant paradigm of well-being, which has emerged in the UK as a justification for many such initiatives: the New Economics Foundation's (2008) Five Ways to Well-being (NEF Five Ways). The NEF Five Ways is often presented as an evidence-based, medically-informed conceptualisation of activities that people should undertake to maintain good well-being and it is often referred to as being endorsed by the NHS. The five recommendations it makes are that we need to keep active, connect with other people, take notice of the world around us, give (i.e. volunteer), and keep learning. In many ways, it is difficult to argue against the NEF Five Ways; the recommendations it makes have a flavour of 'motherhood and apple pie', a conceptualisation that no one could disagree with could never do harm.

However, the evidence behind the NEF Five Ways is in fact limited, drawing on grey literature rather than peer-reviewed journal papers and reinforces a particular agenda: that of the individualistic account of well-being as something that is led by and in the control of the individual without reference to social structures (Rose, 1999, Shaw and Taplin, 2007). This widespread adoption of a simplistic conceptualisation of what well-being is can be seen to be problematic for a number of reasons. First, it ignores social structures and power relationships in favour of what scholars such as Cieslik (2017) would regard as superficial tips that do not encourage well-being in any profound sense. Second, it places the onus on the individual and so reinforces social structures that are problematic by inhibiting social collaboration and action (Rose, 1999). Third, it constructs well-being as 'a problem about which something can and ought to be done' (Baachi quoted in Shaw, 2010). Finally, it is used to semi-pathologise poor well-being and to conflate issues of poor well-being and poor mental health. The provision of services that are seen to improve well-being (within this conceptualisation of the term) is replacing a need to provide good quality and evidence-based mental health care services.

Thus Brewerton and Woolley's (2017) use of the NEF Five Ways could be said to reflect wider issues employing hazy conceptualisation of well-being. The idea of 'living well' is something that is much debated and little agreed on (Dodge, 2012). Rather than something that is easy to define, it is an issue that humans have considered for centuries from a variety of theoretical and 
disciplinary perspectives (Nussbaum, 2005). There is a need for a well-considered definition of the concept, linked to an evidence base of what affects well-being and exploration of measures of impact. However, practitioner papers focus on looking for 'quick fixes' for well-being rather, for example, than helping students to identify and live by deeply-held values.

Though these issues of definition may be dismissed as not important to the overall agenda of well-being related activity, it leads to a superficial construction of the problem which affects evaluation of the effectiveness of any interventions. Similar critiques have been made around the evaluation of well-being in arts interventions (Oman and Taylor, 2018). Thus, for example, Brewerton and Woolley (2017) evaluate one of the activities they organise, pet therapy, thus: "It is great to watch students go from stressful to successful with the help of our furry friends." As if it were merely a matter of petting a dog to gain an immediate impact on mental health and assuming that well-being were simply to be linked to student success. Houghton (2019) assumes that because its popular seeing an owl improves well-being. In fact, examining the literature on pet therapy and the impact on mental health suggests that the available evidence is incomplete, and little research has examined the role of pets as therapy in the university context (Ward-Griffin et al, 2018, Wood et al, 2017). There is certainly some evidence that living with a dog has benefits that might be associated with good well-being, including physical benefits such as regular exercise (Friedmann and Son, 2009). These studies are not considered to be conclusive proof of cause-and-effect, but identity some association. However, living with a companion animal and interacting regularly with them is not the same as having infrequent access to a dog for a short period of time. The extrapolation from the wider evidence base to the university context also causes some cause for concern as it may not correctly be identifying what it is about having access to a pet that has an impact on good well-being. Several more recent studies have examined interventions that specifically bring in therapy animals to a university space. They conclude that any effect on well-being is short-lived; 'the therapy dog sessions did not have a lasting effect on happiness, positive affect, or life satisfaction, suggesting that the effects are somewhat selective' (Ward-Griffin et al, 2018).

The claims made by the authors of collection of papers about the role of well-being activities in the academic library are diverse, but broadly state that it will reduce stress for students, and lead to greater academic success. Evidence produced to support these claims is lacking. Statistics on student stress levels, or impacts on academic achievement are not presented. Houghton (2019) candidly admits that no formal evidence of attendance, let alone impact was 
gathered for the events at Middlesex. Yet there are widely accepted measures of well-being, such as WEMWBS. There is potential to measure the impact of interventions by the library on well-being.

A complication, however, is that even if these data were available, it would still not be easy to establish causality between the well-being related activities in the library and student well-being or an increased level of achievement. Demonstrating an effect in a way that might be acceptable in a medical context is probably impossible, for example. The ultimate issue for academic libraries is that the way in which evidence is constructed in medicine is not available to access, or appropriate, for complex interventions such as these. This poses a continuing problem for any initiative around well-being in terms of credibility. We would suggest following the model proposed by Cieslik (2017) of exploring people's own narratives of well-being as evidence.

In the absence of any very clear definition or substantial evidence for impact on well-being, Houghton (2019) emphasize the effectiveness of the owl as a symbol for the media campaign to attract attention. Similarly, the "effective campaign" for Smith (2019) is to advertise the events rather than evidence of its actual impact. Brewerton and Woolley (2017) also seem to measure success by the response in social media, as if this were merely a marketing campaign. They focus much attention on a penguin mascot used to coordinate their message. The same impression is conveyed by the pictures used to illustrate the article. These include images of students giving a thumbs up and holding a banana in their mouths to look like smiles. The activities seem to be evaluated more as if they were a library promotion campaign rather than one addressing well-being; 'good PR for a caring university!' These pictures in the paper seem to reflect performing well-being rather than encouraging genuine well-being. Indeed, the whole playful style of the paper could be seen as performing a sort of glibly happy tone, one that is potentially at odds with a serious minded response to issues of well-being.

\section{Identifying the true nature of the problem}

Thus fundamentally there is no coherent notion of well-being underlying the activities described in these papers and correspondingly the ways success are measured are superficial. A related issue is a failure to fully understand the nature of the problem around well-being. As context for the library activities for student well-being, Brewerton and Woolley (2017) refer to evidence of a 
rising level of mental health problems among students, as reported in a 2015 Universities UK (UUK) guide (Universities UK, 2015). Smith updates this referring to a ministerial directive from 2018. However, when we analyse the activities that the libraries organise to tackle this shift, they seem largely to be addressing familiar, long-standing issues such as examination stress. What the articles do not do is ground any activity in an understanding of why there is an increasing sense of a problem around well-being and mental health in society and in universities in particular. Clearly a failure to identify the true nature of the problem will mean that attempts at a solution are potentially misdirected. Thus it is essential in responding to any "crisis" around student well-being to give consideration to why this crisis being identified and what are seen as the underlying causes.

We would argue that such an analysis should recognise fundamental societal factors as creating the problem (Baik, et al. 2017). Young people's lives are increasingly pressurised and precarious: the job market is uncertain, access to home ownership more restricted. Political uncertainty, such as around Brexit, seems to be linked to feelings of depression. Meanwhile, climate change and global population growth all create long term uncertainties. These society level troubles should be recognised for what they are. Ultimately these are stresses that need to be addressed at a social level by governments.

However, often the well-being agenda is being used to deflect attention away from such structures. The "problem" of well-being is often being framed through discourses of "neoliberalisation" where, rather than acknowledge that there could be structural reasons for why students' well-being is under pressure, typically social responsibility for their welfare is displaced onto individuals themselves. The issue is misidentified as an individual rather than a social one (Cieslik, 2014; DeVerteuil and Golubchikov, 2016).

Thus many arguments around well-being bear the classic hallmarks of neo-liberalism. For example, Layard (2005) has suggested that we can improve the economic outcomes of the country by improving well-being. This has been very influential as a neoliberal argument for why governments should care about well-being. Layard's (2005) work reinforces two interlinked ideologies; first that having good well-being means we are productive, and second that to have good well-being we need to be productive. 
One example of how the articulation of values has shifted can be seen in the use of the employability agenda in universities (Stoten, 2018). The drive towards productivity and employability as a focus for university rather than education and a spirit of self-discovery means that the focus of university education has changed, and in some ways relationships between universities and students have been damaged. The marketisation of higher education positions the student as consumer and individual rather than social learner.

Instead of questioning the shift in discourse away from education and towards productivity that creates a potentially toxic, more competitive environment, academic libraries are effectively supporting the new institutional culture by providing activities that aim to improve well-being (as conceptualised as an individual problem) rather than questioning why well-being is poor.

In contrast, we would argue, the focus should be on the structures: the precarity of unemployment, under-employment, expectations of productivity and wealth, and expense and scarcity of housing, geopolitical issues and climate change and so forth.

Furthermore, all the five authors discussed here present their discussion of improving well-being as an aspect of student support, with no mention of university staff well-being. When correctly understood the issues of student well-being are tied closely to those of staff (Morrish, 2019). Gill (2009) has argued that anxiety among academics is being created by precarity: temporary contracts, increased metrics on performance and the collapse of the divide between home life and work. Again, she suggests that increasing stress and so the means to address it, is construed in terms of individuals' ability to cope, rather than underlying structures that produce the problem. This is exactly the type of misrecognition that seems to be reproduced in these practitioner papers.

Recognising the nature of the problem properly and fully, logically affects the nature of the response. The logic would be that libraries should be reflecting on how their own practices and processes as a whole impact student (and staff) experience in the context of structural pressures on them, and less focus on developing some sort of additional well-being related service. The shift to addressing students as customers may be counter-productive in this context: for it is precisely market based relations that create a lack of well-being. A very simple example would be to consider how the system of late library book return fines impacts on students who may increasingly be concerned about money. Again, thinking about the UX of libraries that create homely or calm places for study are highly relevant to promoting well-being, particularly if students are struggling with finding such spaces. Taking this further would imply 
reconsidering all services, specifically in the light of structural pressures in student lives. An increasing interest in how libraries fit into the lives of different types of users and recognition of diversity in experience, is a promising direction for optimising their contribution in this context.

If libraries need to reconsider how all their own practices might be implicated in a competitive ethos associated with neo-liberalisation, then they may be able to return to a focus on exploring learning for itself. Fortunately, in many ways libraries already do implicitly resist competitive, individualising ideologies through core services, such as through their emphasis on access to knowledge supported by training in information and digital literacies. This can be critical to ensuring students experience learning in empowering ways. In this sense one could argue that effectively library services already contribute in a profound way to a notion of learning for itself that resists neo-liberal agendas; in so doing they address the issue of well-being.

\section{Locating the problem and solutions within the LIS professional knowledge base}

The failure to define well-being clearly, to measure impacts of interventions or to analyse the nature of the issue could all be seen as reflecting a lack of a sound basis for activity in wellbeing in the professional knowledge base: the third issue we identify as surfacing in the emerging professional literature in the UK.

Brewerton and Woolley (2017) use two arguments for the appropriateness of library involvement in activities relating to student well-being, both with implications for professional identity that need to be carefully considered. Firstly, they draw a link between their well-being related activities and the library strategy. The library strategy further aligns to the university strategy, and this aligns with UUK policy, they point out. So their argument posits that the services are justified because they align to wider circles of strategy. The first step in the chain of this argument is a little tenuous, because they try to tie well-being to the mission of the library of "connecting you with information, support and your community". A more conventional understanding of the reference to support here would interpret this as referring to support for information activities related to study. On its own this does not seem a convincing basis for creating well-being-related services. Both Houghton (2019) and Smith (2019) link their initiatives in a similar way to the integration of the library into institutional life. It is a little unclear what the 
library brings to the table in these collaborations that is distinctive. It becomes merely a host for wider initiatives.

We also suggest that their argument of strategic positioning relies on a top-down a model of alignment. Simply aligning to wider agendas in itself, without applying professional judgement to the purposes is a superficial approach. It would be a stronger case if the library would be seen to seeking to align in a way appropriate to its existing services; this does not seem to be the authors' suggestion. Instead, they are effectively reproducing managerialist discourses around alignment of activities to wider strategy. This can be construed as an anti-professional discourse, in which the autonomy of professions is seen as needing to be suborned to wider organisational needs, especially as it requires the library to do things that do not normally find a place in the library.

The second way in which Brewerton and Woolley (2017:19) seek to justify well-being related activities in the library is by assembling an argument that "libraries have the staff, relationships, skills, spaces and pedigree" to create services for student well-being. Some parts of this argument indeed have a degree of plausibility. Libraries are important places for study. Librarians may often been quite well connected to refer or signpost students to relevant services (but the library is not normally the obvious place to seek different sorts of guidance).

A particular style of argument the authors employ is to claim that well-being related activities are like something libraries have "always done". There is a tenuous connection made between holding coffee mornings for researchers in the library to the history of the coffee house as a place to engage in information sharing and networking, seemingly echoing Habermas' (1989) notion of the public sphere. Quite apart from the socially privileged nature of the coffee houses (Brewer, 1997), the public sphere is about open debate and free information; it has no link to well-being as such. Thus, there is a logical fallacy about making a connection as Brewerton and Woolley's (2017) work does here. Other examples of activity mentioned seem to relate to other university agendas such as internationalisation, rather than to well-being as such.

Fundamentally the authors trace a link between well-being activities and the role of "community outreach", specifically to student support. But generally speaking we would think of community outreach as implying things like information, digital and academic literacy training. Extending this concept to encompass well-being seems quite a leap. In making this leap the authors 
exploit the failure to define their terms and to elide mental health issues, well-being and student performance.

Furthermore, the idea that the library is a natural place for these activities involves a considerable idealisation of library relations with students. It is certainly true that students spend a lot of time at stressful parts of year in the library, as Brewerton and Woolley (2017) state. However, is the claim about students made in the following sentences really true?

"They know the staff. They know we are looking out for them. If we notice they are stressed and talk to them about looking after themselves, this feels natural... They tell us things they wouldn't tell their tutors. They don't feel they have to put on a 'front' with us. " (p.15)

In the context of mass institutions with increased student numbers and trends towards selfservice and disintermediated services, this seems an inflated claim. Thus the attempt to present work about well-being as a natural role for the library seems tenuous.

The form of the argument the authors use links to a very common issue in the library literature and in library practice: how to define the purpose of the library and the library profession in the context of digital and other potential threats to understanding of the value of libraries. The library literature has a preoccupation with librarian identity and library futures. There appears to be a constant need to define and usually reinvent the role of the library. Certainly there is a case for this work since there is no doubt that the traditional "jurisdiction" of the profession, linked to a role in collection needs revision (Abbott, 1998). Many librarians feels frustrated by the continuing identification of their job with the book collection. Given the prominence of well-being in current agendas, it is natural that libraries would consider latching on to it to demonstrate their value.

However, there are fundamental problems with unconsidered expansion of the scope of any profession. Walton $(2007,2018)$ points to the risks to libraries of such "diversification." At a more theoretical level, as Abbott (1988) argues, a profession is a knowledge-based occupation. It claims jurisdiction over workplace tasks on the basis of its special knowledge of how to define and fix problems. But in the accounts of all these authors there is almost no attempt to draw on library theory to underpin a role in student well-being. This is apparent in the earlier points about a lack of a clear definition of well-being and reaching out in a muddled way to Maslow's (1943) work, in Brewerton and Woolley (2017). The authors are casting about to find a reference point, 
but find none in the professional librarianship literature. Yet without some foundation in professional knowledge, the long term sustainability of any claim to involvement in work on student well-being seems implausible. Without some expertise on what well-being means and how to address it, initiatives are unlikely to have great plausibility. Indeed it may even become damaging because it further confuses what a library is and what being a librarian means.

There are two counter arguments that one could make against our reasoning at this point. One counter argument would be to reflect on the trend towards integration or "collaboration" with other student services that at its strongest in some institutions has led to the fusion of the library with other student-facing services in superconvergence (Bulpitt, 2012; Heseltine et al., 2009). In this context the desire to be contributing to student well-being seems more explicable because the library is reconceived as just one service point for all student-centred services. This is more or less, exactly what Porritt (2019) argues about the case for well-being services at Teesside: it is an opportunity to integrate the library with a new department of Student and library services.

This is not inconsistent with our argument about deprofessionalisation, since superconvergence is essentially a de-professionalising trend. For some this may even be welcomed, if one believes that a profession has to give ground to institutional needs. Yet the problem remains in that without some substantive knowledge base behind an understanding of well-being it is hard to see how there can be a sustainable service of value in the library around well-being. Even in a super-converged service there are more obvious service points where well-being could be addressed than the library.

Another counter argument against our point (that the problem with locating well-being in the library is that the profession has no expertise in this area) is to recognise that there is in fact a body of literature that does articulate the role of the library in well-being: namely bibliotherapy (McNicol and Brewster, 2018). It is surprising that bibliotherapy is not a more important reference point for the current work around well-being and the academic library. It is not mentioned in any of the articles considered here, though Porritt's (2019) paper does emphasise reading for leisure and reading groups. Smith (2019) briefly mentions book chats. Although there are some examples of schemes in academic libraries (see, for example, Azadbakht and Englert, 2018), bibliotherapy has historically been mostly practised in public and hospital libraries and few academic librarians have a firm knowledge of it. Another reason that bibliotherapy may not have a central role in the academic library may be that it is founded on the 
notion of books and reading offer benefit to well-being. This could be seen as reinforcing received notions of what a library is and the associated image "problem." For advocates of the diversification of the academic library this might be seen as regressive. Yet bibliotherapy presents the most substantial development of thinking about well-being in the LIS professional literature. Current thinking in the bibliotherapy literature often draws on a "Books on Prescription" model, in which doctors are encouraged to prescribe books instead of/ in addition to medication or other therapies. A list of approved reading, which is usually cognitive behavioural therapy (CBT)-based literature, is then made available via the library. Where bibliotherapy has been adopted in the academic library, this model has continued to dominate. While other models do exist, e.g. where creative works are recommended, these have not been widely taken up in the academic library as their adoption would involve a significant amount of financial and spatial resource. However, evidence suggests that having a broad collection with a range of fiction and non-fiction and giving readers the choice to select their own texts can improve well-being, since there is a lot of individual variation in what reading people find improves their well-being (Brewster, 2016).

Thus we would argue that if libraries develop services related to well-being they must find ways to explain why this is relevant, clearly justified within the professional knowledge base. One route may be to locate it in the professional knowledge base developed in the bibliotherapy literature. This is rooted firmly in having part of the collection that is specifically CBT literature or to encourage reading for well-being.

\section{Discussion}

The papers discussed here are engagingly written reflections on academic libraries' vigorous response to the trend to develop services around student well-being. They are just a few examples of initiatives mirrored in many universities in the UK in the last couple of years, as well as in public libraries, archives and museums. We have chosen to analyse these papers in some depth, not particularly to single out these well-intentioned authors, but because their arguments seem to exhibit problems that occur across the sector in seeking to justify activities around wellbeing.

Our argument in this paper is not that libraries (archives and museums) do not contribute to well-being or that they could not do so more, but to identify three interrelated challenges that 
exist to developing successful services around well-being. Firstly, there is a need to define clearly what well-being is. One convincing approach is to acknowledge the complexity of wellbeing and to ask questions about how people themselves experience it and how the library can play a role in it. In the context of responding to policy pressures, another approach is to follow attempts to measure effects on well-being, given policy makers investment in measures of wellbeing. Without such evidence it is unlikely that such initiatives will be taken seriously by policy makers. Secondly, and relatedly, there is a need to define the nature of the "crisis" around wellbeing. We would argue that this relates to deep-rooted structural issues and fundamental governmental decisions: it relates to issues around the future of youth, falling social mobility and increasing social expectations, combined with a long-term failure by governments to spend money on mental health services. It is strongly linked also to the well-being of staff in academic institutions, including in libraries. It is a misidentification to represent well-being as an individual problem. Information professionals' activities in this area should be directed to analysing and addressing underlying causes and reflecting on whether some aspects of library rules and processes themselves reproduce these effects. We should be wary of aligning to neo-liberal assumptions about the nature of well-being. The third, interlinked, challenge is that the failure to define well-being or analyse its causes echoes a lack of deep engagement with the topic in the literature of our field. Most of the papers reflect a perceived need to align to institutional strategies, but this is not really grounded in the knowledge base of librarianship as a professionalised occupation. A sustainable response from the profession to the "crisis" in wellbeing needs to be rooted in the professional knowledge base. It is curious that the current wave of activity in academic libraries neglects to reference the ways some scholars of bibliotherapy have linked libraries to well-being and reading. It also reflects that very little theorising around academic libraries really has anything to say about well-being. To move into this area in ways not supported by its professional knowledge base has perils for a profession.

It should be clear from what we have written that we are far from rejecting the idea of a role for the academic library in well-being. Rather it is about reflecting on libraries' role in higher education as a whole and where new initiatives are needed, locating them correctly: defining the concept and the nature of the underlying issues, measuring impact in ways that are convincing to policy makers and developing a very clear narrative of how this activity relates to the role of the library. 


\section{Conclusion}

This paper is an attempt to respond positively but critically to the current trend towards providing support to student well-being in the academic library. The purpose is to prompt a deeper engagement with the underlying concept. There is a need to engage with wider debates about the meaning of well-being, underlying causes of the current concerns and the growing evidence base on what works to improve well-being. One starting point is certainly the literature of bibliotherapy, which is strangely missing from the existing academic library debate.

The debate has considerable implications for professional identity. It is one that is happening across our sector, touching archives, museums as well as libraries. There is a need for a systematic analysis of current initiatives and their rationale. From one perspective this would tell us about how academic libraries are evolving. On the other hand, it would need to be interpreted within much wider trends in academia and society about how cultural services are valued under neo-liberalisation.

We may find that libraries already contribute in a profound way to well-being in the university through the kind of belonging that many students find in library spaces and in the notion of access to learning they inherently promote.

\section{References}

Abbott, A. (1988). The system of professions: An essay on the division of expert labor. Chicago: University of Chicago press.

Abbott, A. (1998). Professionalism and the future of librarianship. Library Trends, 46 (3) 430433.

Azadbakht, E. and Englert, T. (2018). Promoting student wellbeing through a student success collection. In McNicol, S. and Brewster, L. (Eds) (2018). Bibliotherapy. London: Facet. Baik, C., Larcombe, W., Wyn, J., Allen, L., Brett, M., Field, R. James, R. (2017). Enhancing student mental well-being: A handbook for educators. https://melbournecshe.unimelb.edu.au/ data/assets/pdf file/0006/2408604/MCSHE-Student-WellbeingHandbook-FINAL.pdf 
Bell, A. (2013). Paws for a study break: Running an animal-assisted therapy program at the Gerstein Science Information Centre. Partnership: The Canadian Journal of Library and Information Practice and Research, 8(1).

Brewer, J. (1997). Pleasures of the imagination : English culture in the eighteenth century.London: HarperCollins.

Brewerton, A. and Woolley, B. (2017). Study happy: Library wellbeing initiatives from the University of Warwick. Sconul Focus 68 15-25.

Brewster, L. (2016). More benefit from a well-stocked library than a well-stocked pharmacy: How do readers use books as therapy?, in: Rothbauer, P., Skjerdingstad, K.., McKechnie, E.F., Oterholm, K. (Eds.), Plotting the Reading Experience: Theory/ Practice/ Politics. Wilfred Laurier University Press, Waterloo, Ontario, pp. 167-182.

Brunton, B. (2018). Using archives to improve mental wellbeing. https://blog.nationalarchives.gov.uk/using-archives-improve-mental-wellbeing/ [accessed 9 May 2019]

Bulpitt, G. (Ed.) (2012). Leading the student experience: Super-convergence of organisation, structure and business processes. Leadership Foundation for Higher Education Research and Development Series, Series 3: Publication 5.

Casucci, T., \& Baluchi, D. (2019). A health sciences library promotes wellness with free yoga. Journal of the Medical Library Association: JMLA, 107(1), 80.

Cieslik, M. (2014). Not Smiling but Frowning: Sociology and the "Problem of Happiness." Sociology. https://doi.org/10.1177/0038038514543297

Cieslik, M. (2017). The Happiness riddle and the quest for a good life. Palgrave Macmillan, Basingstoke.

Desmarais, S., Bedford, L. \& Chatterjee, H.J. (2018). Museums as Spaces for Wellbeing: A Second Report from the National Alliance for Museums, Health and Wellbeing.

Available at: www.museumsandwellbeingalliance.wordpress.com

DeVerteuil, G., Golubchikov, O. (2016). Can resilience be redeemed? Resilience as a metaphor for change, not against change. City 20, 143-151.

Dodge, R., Daly, A., Huyton, J. \& Sanders, L.D. (2012). The challenge of defining wellbeing. International Journal of Wellbeing 2(3): 222-235.

Friedmann, E., \& Son, H. (2009). The human-companion animal bond: how humans benefit. Veterinary Clinics of North America: Small Animal Practice, 39(2), 293-326. doi:

10.1016/j.cvsm.2008.10.015. 
Gill, R. (2009). Breaking the silence: The hidden injuries of neo-liberal academia in Flood,R. \& Gill,R. (Eds.) Secrecy and Silence in the Research Process: Feminist Reflections. London: Routledge.

Habermas, J. (1989). The structural transformation of the public sphere : An inquiry into a category of bourgeois society. Cambridge, Mass.: MIT Press.

Heseltine, R., Marsh, S., McKnight, S. \& Melling, M. (2009) Super-convergence SCONUL shared-experience meeting, 16 February 2019. SCONUL focus 46 121-124.

Houghton, R. (2019) Owl about that? The use of animals to engage students with library service. ALISS Quarterly 14 (2) 13-15.

Lackoi, K., Patsou, M., \& Chatterjee, H.J. (2016). Museums for Health and Wellbeing.

A Preliminary Report, National Alliance for Museums, Health and Wellbeing. Available at: https://museumsandwellbeingalliance.wordpress.com [accessed 9 May 2019]

Layard, R., 2005. Happiness: lessons from a new science. Penguin, London. Maslow, A. H. (1943). A Theory of Human Motivation. Psychological Review, 50(4), 370-96. McNicol, S. and Brewster, L. (Eds) (2018). Bibliotherapy. London: Facet. Morrish, L. (2019). Pressure vessels: The epidemic of poor mental health among higher education staff. HEPI occasional paper 20. Available at https://www.hepi.ac.uk/wpcontent/uploads/2019/05/HEPI-Pressure-Vessels-Occasional-Paper-20.pdf [accessed 9 May 2019]

New Economics Foundation (2008) Five Ways to Wellbeing: A report presented to the Foresight Project on communicating the evidence base for improving people's well-being. https://neweconomics.org/uploads/files/8984c5089d5c2285ee t4m6bhqq5.pdf [accessed 9 May 2019]

Nussbaum, M.C. (2005). Wellbeing, Contracts and Capabilities. In: Manderson L (ed.), Rethinking Wellbeing, Perth: API Network.

Oman, S \& Taylor, M. (2018). Subjective well-being in cultural advocacy: a politics of research between the market and the academy. Journal of Cultural Economy. 11. 1-19.

10.1080/17530350.2018.1435422.

Porritt, F. (2019). Festival of Wellbeing at Teesside University. ALISS Quarterly 14 (2) 16-17. Rose, N. (1999). Governing the Soul: The Shaping of the Private Self. Routledge, London. Shaw, I. \& Taplin, S. (2007). Happiness and mental health policy: a sociological critique. Journal of Mental Health 16, 359-373. 
Shaw, S.E. (2010). Reaching the parts that other theories and methods can't reach: how and why a policy-as-discourse approach can inform health-related policy. Health. 14, 196-212. https://doi.org/10.1177/1363459309353295

Stoten, D. (2018). Employability: A Contested Concept in Higher Education. Journal of Pedagogical Development 8 (1)

Universities UK (2015). Student mental wellbeing in higher education: good practice guide. Available from: https://www.universitiesuk.ac.uk/policy-and-analysis/reports/Pages/studentmental-wellbeing-in-higher-education.aspx [accessed 15 May 2019]

Varman, B. G., \& Justice, A. V. (2015). The unfunded worksite wellness program. Journal of Hospital Librarianship, 15(3), 284-295.

Walton, G. (2007). Library Management: theory, research and practice in library management 3 : diversification. Library Management, 28 (6/7) 428-436.

Walton, G. (2018). Supporting student wellbeing in the university library: A core service or a distraction? New Review of Academic Librarianship 24 (2) 121-123.

Ward-Griffin, E., Klaiber, P., Collins, H. K., Owens, R. L., Coren, S., \& Chen, F. S. (2018).

Petting away pre-exam stress: The effect of therapy dog sessions on student well- being.

Stress and Health, 34(3), 468-473.

The Warwick-Edinburgh Mental Wellbeing Scales - WEMWBS (2018). Availabel from: https://warwick.ac.uk/fac/sci/med/research/platform/wemwbs/ [accessed 7 August 2019]

Wise, M. J. (2018). Naps and sleep deprivation: Why academic libraries should consider adding nap stations to their services for students. New Review of Academic Librarianship, 24(2), 192210.

Wood, E., Ohlsen, S., Thompson, J., Hulin, J. \& Knowles, L (2018) The feasibility of brief dogassisted therapy on university students stress levels: the PAwS study, Journal of Mental Health, 27:3, 263-268, DOI: 10.1080/09638237.2017.1385737 